\title{
SPECTRUM OF BENIGN BREAST DISEASES ON A REMOTE INDIAN ISLAND
}

\author{
Gargade C.B1, Deshpande A.H²
}

${ }^{1}$ Associate Professor, Department of Pathology, Andaman \& Nicobar Islands Institute of Medical Sciences, Port Blair. 2Professor and HOD, Department of Pathology, Andaman \& Nicobar Islands Institute of Medical Sciences, Port Blair.

\section{ABSTRACT}

\section{BACKGROUND}

Lump in the breast has assumed increasing importance in recent years because of the public awareness of breast cancer. Benign lesions of breast are the most common lesions and constitute a heterogeneous group of disorders including developmental abnormality, epithelial and stromal proliferation, inflammatory lesions and neoplasm. Few benign proliferative lesions have been reported to be at increased risk for development of subsequent breast cancer.

The aim of the study is to study the frequency of various benign breast diseases in the females.

\section{MATERIALS AND METHODS}

This descriptive study of histopathologically diagnosed breast lesions was carried out in the Department of Pathology of a newlyestablished medical college from January 2016 to May 2017. The incidence of benign breast lesions was found to be $78.6 \%$ of all breast lesions. Most of the benign breast lesions were seen below age of 40 yrs. (86.14\%); 38.27\% (31/81) patients belonged to third decade of life (21-30 years) followed by 25.92\% (21/81) in second decade (11-20 years) and 22.22\% (18/81) from fourth decade (age between: 31-40 years). Fibroadenoma was the most common benign breast disease seen in 62.96\% (51/81) of patients followed by fibrocystic disease in about 8.64\% (7/81) patients. Bilateral gynaecomastia was the most common benign disease seen in all male patients.

\section{CONCLUSION}

Benign breast diseases were more common than malignancies in our study. Fibroadenoma was the commonest of all benign breast diseases. Fibroadenoma was seen more commonly in second and third decade, while fibrocystic disease was seen in little older patients.

\section{KEYWORDS}

Breast, Benign Breast Diseases, Fibroadenoma.

HOW TO CITE THIS ARTICLE: Gargade C.B., Deshpande A.H., Spectrum of benign breast diseases on a remote Indian Island. J. Evolution Med. Dent. Sci. 2017;6(73):5238-5241, DOI: 10.14260/Jemds/2017/1137

\section{BACKGROUND}

Around $50 \%$ of women in their lifetime experience breastrelated signs and symptoms. All breast lesions are not malignant. Globally, Benign Breast Diseases (BBD) are the most common lesions accounting $90 \%$ of breast related clinical presentations. ${ }^{1}$

BBD includes all non-malignant conditions of the breast, including benign tumours, trauma, mastalgia, mastitis and nipple discharge. Benign tumours include pathologic changes that do not increase a patient's risk for developing cancer, lesions that confer a slightly increased risk and lesions that are associated with up to $50 \%$ risk of developing breast cancer. $^{2}$

Hence, it is essential to recognise and study these lesions in detail.

\section{Aims and Objectives-}

The aim of this study was to find the frequency of various benign breast diseases in females. The objective was to find the incidence of various benign breast lesions in different age groups.

Financial or Other, Competing Interest: None.

Submission 31-07-2017, Peer Review 27-08-2017,

Acceptance 01-09-2017, Published 11-09-2017.

Corresponding Author:

Dr. Deshpande A.H.,

Professor and HOD, Department of Pathology,

Andaman \& Nicobar Islands Institute of Medical Sciences,

Port-Blair-744101.

E-mail: ahdesh@gmail.com

DOI: $10.14260 /$ jemds/2017/1137

\section{MATERIALS AND METHODS}

This descriptive study of 81 cases of histologically diagnosed benign breast lesions was carried out in the Department of Pathology, at newly-established teaching hospital on an Indian Island from January 2016 to May 2017. Since all cases were taken from record of Pathology Department, ethical consideration was not necessary. Male and female patients of all age group with biopsy-proven benign diseases of the breast were included in this study. Patients with biopsyproven malignant diseases and inadequate core biopsies were excluded from present study. The demographic characteristics of patients were presented in excel sheet and analysed for the frequency of each lesion and their distribution in various age group.

\section{RESULTS}

During study period, 107 breast samples were received in Department of Pathology in the form of modified radical mastectomy, lumpectomy, wedge biopsy and core biopsy. All core biopsies (4/107) received were inadequate to report, hence excluded from study. On histopathological examination of 103 cases of breast lesions, 81 (78.64\%) were benign and $21.36 \%$ were malignant. Out of 81 benign lesions, 77 $(95.06 \%)$ were seen in female and $4(4.94 \%)$ were seen in male. 


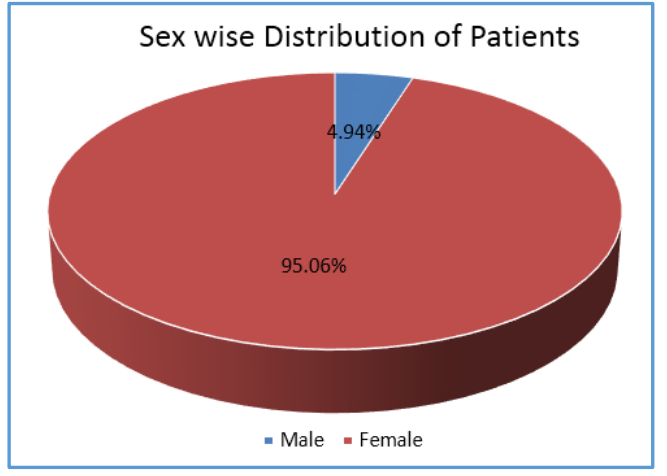

Figure 1. Sex Wise Distribution of Benign Breast Diseases

Commonest benign breast lesion in female was fibroadenoma (62.96\%), followed by fibrocystic disease (8.64\%). Distribution pattern of benign breast disease is shown in Table 1.

\begin{tabular}{|c|c|c|c|}
\hline Sl. No. & Type of Lesions & $\begin{array}{c}\text { No. of } \\
\text { Cases }\end{array}$ & $\begin{array}{c}\text { Percentage of } \\
\text { Total Benign } \\
\text { Breast Lesions }\end{array}$ \\
\hline \multicolumn{4}{|c|}{ Lesions in Female } \\
\hline 1. & Breast abscess & 6 & 7.4 \\
\hline 2. & Fat necrosis & 1 & 1.23 \\
\hline 3. & Mammary duct ectasia & 1 & 1.23 \\
\hline 4. & Fibrocystic disease & 7 & 8.64 \\
\hline 5. & Epidermal inclusion cyst & 3 & 3.7 \\
\hline 6. & Axillary breast & 3 & 3.7 \\
\hline 7. & Hamartoma & 1 & 1.23 \\
\hline 8. & Lactating adenoma & 2 & 2.46 \\
\hline 9. & Fibroadenoma & 51 & 62.96 \\
\hline 10. & Benign phyllodes & 2 & 2.46 \\
\hline \multicolumn{4}{|c|}{ Lesions in Male } \\
\hline 1. & Gynaecomastia & 4 & 4.93 \\
\hline \multicolumn{4}{|c|}{ Table 1. Distribution and Incidence } \\
of Benign Breast Lesions \\
\hline
\end{tabular}

Age distribution pattern reveals most of the cases of benign breast lesions were found below 40 years of age in third decade followed by second decade.

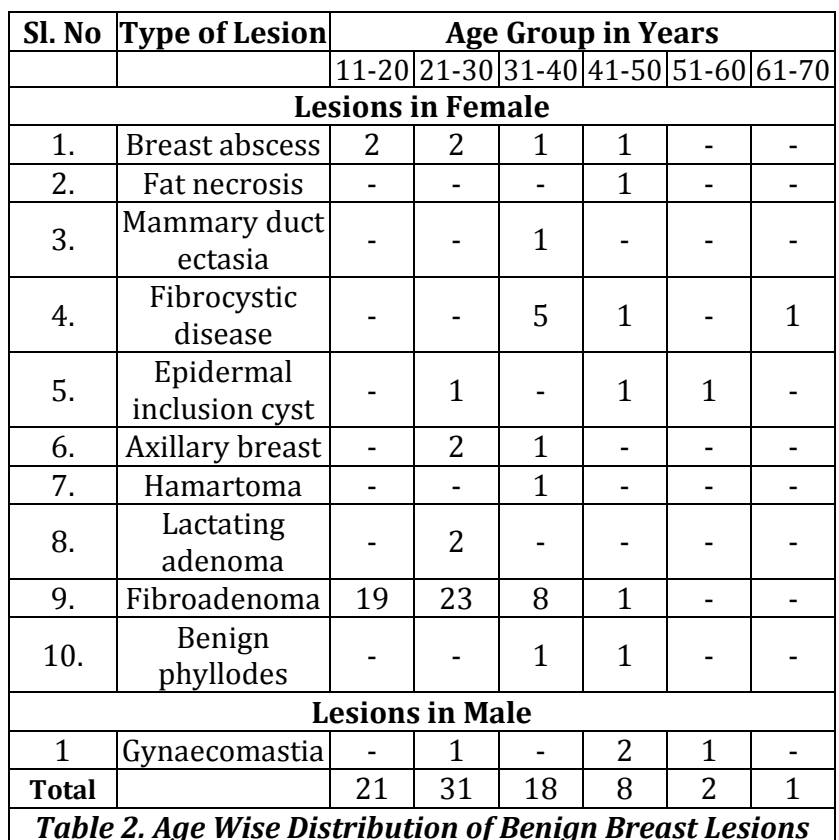

Fibroadenoma 51 (62.96\%) was the most frequent diagnosis encountered in female followed by fibrocystic changes, which constituted $8.64 \%$ of the BBD. Most of the fibroadenomas were seen in third decade of life 23 (45.09\%), followed by second decade 19 (37.25\%). Eight cases were noted in fourth decade and one case in fifth decade. Fibroadenoma was bilateral in two cases $(3.92 \%)$ and seen in right and left breast in $26(50.98 \%)$ and 23 (45.09\%) cases, respectively. Three cases of fibroadenoma showed myxoid change and in one case stroma showed lipomatous differentiation.

Fibrocystic disease seen in 7 cases (8.64\%) was the second most common breast lesion with maximum age incidence in the age group of 31-40 years (5/7). Minimum age noted in fibrocystic disease was 32 years and maximum 66 years. In later, case focal mild atypical ductal hyperplasia was noted.

Nonspecific mastitis and breast abscess constitutes 6 $(7.4 \%)$ of all benign breast lesions in female. Other inflammatory lesions included were duct ectasia and fat necrosis.

Epidermal Inclusion Cyst (EIC) of breast accounted for $3.7 \%(3 / 81)$ of benign breast disease in female.

One case of benign phyllodes tumour was seen each in third and fourth decade.

Lactating adenoma was seen in $2.46 \%$ cases.

Adenolipomatous hamartoma of left breast was noted in 35-year-old female.

There were four cases of gynaecomastia. Bilateral gynaecomastia was observed in one case. Maximum age noted in gynaecomastia was 60 years.

\section{DISCUSSION}

In this study, benign breast diseases accounted for $78.6 \%$ $(81 / 103)$ all breast diseases. This finding is in tandem with previous reports from Bagale $\mathrm{P}$ et al, ${ }^{3}$ Rasheed $\mathrm{A}$ et al, ${ }^{4}$ Pudale $S$ et $\mathrm{l}^{5}$ and Sarma $\mathrm{U}$ et $\mathrm{al}^{6}$ where BBDs accounted for $78.5 \%$, $77.7 \%, 71.15 \%$ and $70 \%$ of all breast diseases, respectively.

Similar studies have been documented in other parts of the world where incidence of BBD is similar to our study. In report by Forae GD et al ${ }^{7}$ from Nigeria, BBD constitutes $71.2 \%$ while higher incidence of benign breast disease of $85.2 \%$ is reported by Khan MA et al ${ }^{8}$ from Pakistan.

In our study, about $86.41 \%$ of the patients with BBD were in the age group between 11-40 years with peak incidence $(38.27 \%)$ in age group between 21-30 years. Similar incidence of benign breast disease in the age group 21-30 is reported by Echejoh $\mathrm{G}$ et al from Nijeria. ${ }^{9}$

In study by Khanzada TW et al, ${ }^{10}$ majority of the patients $(82 \%)$ were below the age of 40 years with peak incidence $(43.5 \%)$ in age group between $21-30$ years.

Other studies from India by Vimal $\mathrm{M}$ et al ${ }^{11}$ and Kaki OB et $\mathrm{al}^{12}$ reported higher incidence of BBD of $50 \%$ and $67 \%$ respectively in age group of 21-30 yrs.

In the present study, fibroadenoma $51 / 81(62.96 \%)$ is the most common benign lesion, which is corresponding to Kulkarni et al study ${ }^{13}$ in which fibroadenoma accounted for $62.32 \%$ of benign lesions.

In present study, fibroadenoma was most commonly seen in 23/51 (45.09\%) patients in third decade (21-30 years) of life and in 19/51 (37.25\%) patients during second decade (11-20 years) of life. Similar findings were reported by Hatim 
KS et $\mathrm{al}^{14}$ in his study where majority of fibroadenoma patients belonged to $21-30$ years (43.5\%), followed by 11-20 years (37.4\%) of age group.

In our study, 26 patients of fibroadenoma presented with lump in the right breast (50.98\%) followed by 23 (45.09\%) in left breast. Bilateral fibroadenoma of breasts was seen in 2 cases $(3.92 \%)$. Sangma et al ${ }^{15}$ noted $48 \%$ lesions in right breast and $40 \%$ in left breast, while Bagale $\mathrm{P}$ et al ${ }^{3}$ noted $95 \%$ cases in left breast and rest were detected in both breasts.

Fibrocystic disease of the breast can mimic carcinoma in clinical, radiographic, gross and microscopic appearance. Some forms, especially those that are proliferative and atypical are associated with an increased risk for the development of carcinoma. Fibrocystic disease was the second most common BBD seen in our study (8.64\%). Five out of seven cases $(71.42 \%)$ were from fourth decade while one case $(14.28 \%)$ was from fifth decade and one $(14.28 \%)$ was from seventh decade of life. Female showing fibrocystic disease in seventh decade also showed mild atypical ductal hyperplasia.

Bagale $\mathrm{P}$ et $\mathrm{al},{ }^{3}$ Pudale et $\mathrm{al}^{5}$ and Hatim KS et $\mathrm{al}^{14}$ also noted fibrocystic disease as second common BBD after fibroadenoma accounting for $11.24 \%, 32 \%$ and $4.3 \%$, respectively. Bagale $\mathrm{P}$ et $\mathrm{al}^{3}$ and Shashikala et al ${ }^{16}$ noted most of the cases in fourth decade while Sangma et al ${ }^{15}$ noted most of cases in third and fourth decades. While Chaudhary et al ${ }^{17}$ in his study of 234 patients found fibrocystic disease as the most common BBD with maximum age incident in the fifth decade of life.

Most Indian and other studies elsewhere reported Fibrocystic Change (FCC) as the second most common finding. It is important to note, however, that few studies showed FCC as the most common BBD. ${ }^{18-20}$

Epidermal inclusion cysts of breasts were seen in three female patients constituting $3.7 \%$ of all benign breast lesions. First, histologically defined case of EIC of the breast was reported in December 1900 at The Johns Hopkins Hospital. ${ }^{21}$

EIC of the breast typically affects individuals in the fifth decade of life and males are affected in a small proportion of cases. In present study, all three cases of EIC were seen in female individuals; while age predilection of fifth decade was not noted. International literature has reported 90 cases of EIC of the breast. ${ }^{22}$

Two patients in our study (2.46\%) showed benign phyllodes; one was in forth decade and other was in fifth decade. These findings were compatible with Forae GD and Olu-Eddo et $\mathrm{al}^{23}$ where benign phyllodes tumour constituted $1.8 \%$ of BBDs and most commonly encountered between the third and fifth decades of life. Mudholkar et $\mathrm{al}^{24}$ and Mallikarjuna et $\mathrm{al}^{25}$ noted maximum number of cases in fourth decade, while Pudale et $\mathrm{al}^{5}$ noted most of the cases in fifth decade.

However, our findings are in contrary to the reports by Nzegwu et $\mathrm{al}^{26}$ Irabo and Okolo et $\mathrm{al}^{27}$ and Chalya PL et al ${ }^{28}$ where patients with benign phyllodes were aged below 20 years of age. Benign phyllodes tumour below 20 yrs. of age are rarely reported in Indian literature. ${ }^{29,30}$

Breast abscesses are mostly seen in lactating mothers, but it might occur in female who do not lactate. Breast abscess was seen in six cases in our study accounting for $7.4 \%$ of cases. Four out of six breast abscesses were seen in lactating mothers.

In a study done by Ullah et $\mathrm{al}^{3}, 15 \%$ had breast abscesses. $^{29}$ Breast abscess in study by OB Karki et al ${ }^{11}$ accounted for $11 \%$ of cases and all of them were lactating mothers except one. Similar findings were noted by Khanzada TW et al. ${ }^{10}$

In Indian study, incidence of breast abscess ranges from $1 \%, 1.67 \%$ to $6.5 \%$ as reported by Hatim KS et al, ${ }^{14}$ Pudale S et $\mathrm{al}^{5}$ and Bagale $\mathrm{P}$ et $\mathrm{al}^{3}{ }^{3}$ respectively. In present study, breast abscess were found in patient of age between 21-30 years, which is similar to that observed by Hatim KS et al.14

Lactating adenoma occurred in $2.46 \%$ of the patients and all were in their third decade of life. In a study by Pudale et al, 5 incidence of lactating adenoma was $1.67 \%$ of all benign breast disease and mean age of presentation was $27 \mathrm{yrs}$.

One case of adenolipomatous hamartoma of the breast was reported in our study constituting $1.23 \%$ of all the cases. Two cases of hamartoma $(0.31 \%)$ were reported by Forae et al, ${ }^{7}$ while Pudale $S$ et $\mathrm{al}^{5}$ reported a single case $(0.18 \%)$ in their study.

Fat necrosis is a benign non-suppurative inflammatory process of adipose tissue. It is important to diagnose fat necrosis, because it can often mimic carcinoma of the breast. Fat necrosis in the breast is a common pathologic condition with a wide variety of presentations on mammography, ultrasound and MRI.

A single case of fat necrosis was reported in 50 yrs. old female in our study accounting for $1.23 \%$ of all benign breast lesions, which is similar to that reported by Hatim KS. ${ }^{14}$ Fat necrosis is found to be $0.8 \%$ of breast tumours and $1 \%$ in breast reduction mammoplasty cases. The average age of patients is 50 years. Karki et al noted $121 \%$ cases of fat necrosis while Bagale $\mathrm{P}$ et $\mathrm{a}^{5}$ reported 11 cases $(2.2 \%)$ of fat necrosis. In study by Bagale $\mathrm{P}$ et al, 10 cases of fat necrosis were observed in reproductive age group and one case was seen in sixth decade. The high incidence of fat necrosis mainly in reproductive age group could be secondary to leakage of milk in galactocele or lactating adenoma.

\section{CONCLUSION}

The spectrum of benign breast diseases in our study does not appear to differ much from other studies with fibroadenoma being the most common benign breast lesions. Benign breast disease was observed mainly before 40 yrs. of age. Premalignant condition like atypical ductal hyperplasia was less common in our study and a single case was noted in 60 yrs. elderly female.

\section{REFERENCES}

[1] Murillo OB, Botello HD, Ramírez MC, et al. Benign breast diseases: clinical, radiological and pathological correlation. Ginecología y Obstetricia de México 2002;70:613-8.

[2] Miltenburg DM, Speights VO. Benign breast disease. Obstet Gynecol Clin North Am 2008;35(2):285-300.

[3] Bagale P, Dravid NV, Bagale $\mathrm{S}$, et al. Clinicopathological study of benign breast diseases. International Journal of Health Sciences and Research 2013;3(2):47-54.

[4] Rasheed A, Sharma S, Mohsin-ul-Rasool BS, et al. A three year study of breast lesions in women aged 15- 
70 years in a tertiary care hospital. J App Med Sci 2014;2(1B):166-8.

[5] Pudale S, Tonape SD. A histopathological study of nonmalignant breast lesions. Int $\mathrm{J}$ Res Med Sci 2015;3(10):2672-6.

[6] Sarma U, Deka R, Deuri S. ER \& PR status of breast cancer-a single center study from Guwahati, North East India. Ind J App Res 2015;5(7):283-4.

[7] Forae GD, Nwachokor FN, Igbe AP, et al. Benign breast diseases in Warri, Southern Nigeria: a spectrum of histopathological analysis. Ann Nigerian Med 2014;8(1):28-31.

[8] Khan MA, Shah H, Javed K. Histopathological pattern of 230 benign breast lesions at a tertiary care hospital of Peshawar. KJMS 2016;9(1):128-31.

[9] Godwins E, David D, Akeem J. Histopathologic analysis of benign breast diseases in Makurdi, North central Nigeria. International Journal of Medicine and Medical Sciences 2011;3(5):125-8.

[10] Khanzada TW, Samad A, Sushel C. Spectrum of benign breast diseases. Pak J Med Sci 2009;25(2):265-8.

[11] Vimal M, Chitra T. Spectrum of benign breast diseases in females of reproductive age group. Journal of Research in Medical and Dental Science 2017;4(2):137-40.

[12] Karki OB, Kunwar D, De A. Benign breast diseases: profile at a teaching hospital. American Journal of Public Health Research 2015;3(4A):83-6.

[13] Kulkarni S, Voralla M, Ghorpade $\mathrm{K}$, et al. Histopathological spectrum of breast lesions with reference to uncommon cases. J Obstet Gynecol India 2009;59:444-52.

[14] Hatim KS, Laxmikant NS, Mulla T. Patterns and prevalence of benign breast disease in Western India. Int J Res Med Sci 2017;5(2):684-8.

[15] Sangma MBM, Panda K, Dasiah S. A clinicopathological study on benign breast diseases. J Clin Diagn Res 2013;7(3):503-6.

[16] Shashikala V, Sonia RPB, Victor AJ. Clinicopathological study of benign breast diseases. Int J Biomedical and Advance Research 2016;7(9):424-7.

[17] Chaudhary IA, Qureshi SK, Rasul S, et al. Pattern of benign breast diseases. J Surg Pak 2003;8(3):5-7.

[18] Jeje EA, Mofikoya BO, Oku YE. Pattern of breast masses in Lagos: a private health facility review of 189 consecutive patients. Nigerian quarterly journal of hospital medicine 2010;20(1):38-41.
[19] McFarlane ME. Benign breast diseases in an AfroCaribbean population. East Afr Med J 2001;78(7):35859.

[20] Memon A, Parveen S, Sangrarasi AK, et al. Changing pattern of benign breast lumps in young females. World J Med Sci 2007;2(1):21-4.

[21] Menville JG. Simple dermoid cysts of the breast. Ann Surg 1936;103(1):49-56.

[22] Paliotta A, Sapienza P, D'ermo G, et al. Epidermal inclusion cyst of the breast: a literature review. Oncology letters 2016;11(1):657-60.

[23] Olu-Eddo AN, Ugiagbe EE. Benign breast lesions in an African population: a 25-year histopathological review of 1864 cases. Niger Med J 2011;52(4):211-6.

[24] Mudholkar VG, Kawade SB, Mashal SN. Histopathological study of neoplastic lesions of breast, Indian. Medical Gazette 2012:353-64.

[25] Mallikarjuna, Maralihalli SS. Clinico-pathological study of benign breast disease. Indian Journal of Basic and Applied Medical Research 2015;4(2):39-46.

[26] Nzegwu MA, Adanna A, Daniel O, et al. An unusually early age of presentation of phylloides tumour in Eastern Nigeria. European journal of cancer care 2008;17(3):312-3.

[27] Irabor D0, Okolo CA. An audit of 149 consecutive breast biopsies in Ibadan, Nigeria. Pakistan Journal of Medical Sciences 2008;24(2):257-62.

[28] Chalya PL, Manyama M, Rambau PF, et al. Clinicopathological pattern of benign breast diseases among female patients at a tertiary health institution in Tanzania. Tanzania Journal of Health Research 2016;18(1).

[29] Bhasin SK, Kumari S, Kumar V, et al. Bilateral benign giant phyllodes tumor in an adolescent female: a rare case report. Int Surg J 2014;1(3):177-80.

[30] Makhija D, Shah H, Bothra J, et al. An adolescent with a phyllodes tumor: a case report and review. International Journal of Pediatrics and Adolescent Medicine 2016;3(4):180-3.

[31] Ullah N, Israr M, Ali M. Evaluation of benign breast lump. Pak J Surg 2010;26(4):261-4. 